\title{
O conceito de aglomerado subnormal do IBGE e a precariedade dos serviços básicos de infraestrutura urbana
}

\author{
Larissa Souza Catalá* \\ Roberto Luiz do Carmo*
}

Este artigo aborda as limitações da categoria aglomerado subnormal, do IBGE, para analisar as desigualdades socioeconômicas, habitacionais, demográficas e, sobretudo, de acesso aos serviços básicos de infraestrutura urbana nas cidades brasileiras. Também são considerados os potenciais impactos que as mudanças previstas para o próximo Censo Demográfico terão sobre as análises e as políticas públicas de melhoria das condições de vida urbana. Como metodologia, utilizou-se a análise discriminante para identificar setores censitários classificados como comuns, pelo IBGE, que possuíam características similares às dos setores subnormais, em 2010, nas regiões metropolitanas selecionadas. Em seguida, relacionaram-se os tipos de setores à inadequação dos serviços básicos de infraestrutura urbana e foram analisados os quesitos previstos para serem retirados do próximo Censo, à luz das variáveis que mais discriminaram os setores subnormais dos comuns, segundo as análises realizadas. Os resultados evidenciam que os setores subnormais e os similares identificados não foram suficientes para representar as áreas urbanas com maior demanda de serviços públicos essenciais adequados, em 2010. A localização dos setores reflete muito mais sobre a precariedade dos serviços do que sua condição de "subnormalidade". Destaca-se a relevância da informação sobre o fornecimento de energia elétrica e sobre a condição de ocupação dos domicílios para as análises das desigualdades habitacionais e de infraestrutura urbana, cujas variáveis estão indicadas para serem retiradas do questionário do universo no próximo recenseamento. Finalmente, salienta-se a contínua valorização da propriedade no conceito de "subnormalidade" do IBGE em detrimento da disponibilidade de serviços públicos essenciais adequados nas áreas urbanas.

Palavras-chave: IBGE. Aglomerado subnormal. Análise discriminante. Regiões metropolitanas. Brasil.

\footnotetext{
* Instituto Brasileiro de Geografia e Estatística (IBGE), Rio de Janeiro-RJ, Brasil (larissa.catala@ibge.gov.br; https://orcid. org/0000-0001-8155-1274).

** Universidade Estadual de Campinas (Unicamp), Campinas-SP, Brasil (roberto@nepo.unicamp.br; https://orcid.org/00000003-1063-2266).
} 


\section{Introdução}

Ainda que a intensificação do processo de industrialização em meados do século XX tenha impulsionado o processo de urbanização brasileiro e a crise econômica das décadas de 1980 e 1990 tenha acentuado a exclusão social nas cidades, os problemas urbanos atuais, especialmente no campo habitacional, têm suas origens sobretudo na privatização da terra e na emergência do trabalho "livre" (MARICATO, 2000).

Em um país marcado pela desigualdade no acesso à terra, cujo processo de industrialização não incluiu na renda do trabalhador o custo da habitação (FERREIRA, 2005), em que o Estado sempre atuou a favor dos interesses do mercado imobiliário em detrimento das necessidades da maioria da população urbana (ROLNIK, 1999), deixando de promover a função social da propriedade, a "informalidade" ou "ilegalidade" mostra-se como a única maneira pela qual a população de mais baixa renda tem sua demanda por moradia atendida (D’OTTAVIANO, 2019).

Apesar de os assentamentos originados a partir da ocupação ilegal de terras urbanas serem, historicamente, mais uma regra do que uma exceção (MARICATO, 2019) e não se restringirem às populações pobres (GARDINI, 2009), a condição de ocupação do terreno continua decisiva nas definições utilizadas pelo Instituto Brasileiro de Geografia e Estatística (IBGE), desde 1950, para classificar as áreas urbanas com precariedade na oferta de serviços públicos essenciais.

Dentre essas definições, está o conceito de aglomerado subnormal, utilizado desde 1991, que inclui, além das áreas com “ocupação ilegal da terra no momento atual”, aquelas que eram assim caracterizadas “até período recente” (IBGE, 1991, 2000, 2011b), mostrando que, para o IBGE, o histórico de ocupação ilegal dos assentamentos é mais relevante do que sua condição atual de regularidade (GONÇALVES, 2006). Outros fatores contribuem para limitar a posse legal da terra enquanto condição de "normalidade" das áreas urbanas do país, tais como as frequentes imprecisões nos registros de propriedade (MARICATO, 2000, 2008), a insegurança da posse da moradia mesmo em casos de regularização fundiária (VAINER et al., 2013) e a existência de áreas de ocupação legal, normalmente periféricas, em condições de precariedade de infraestrutura urbana piores do que algumas áreas ocupadas ilegalmente (IBGE, 2011a).

Este artigo tem como objetivo abordar as limitações da categoria aglomerado subnormal, do IBGE, para analisar as desigualdades socioeconômicas, habitacionais, demográficas e, sobretudo, de acesso adequado aos serviços básicos de infraestrutura urbana nas cidades brasileiras, considerando as informações do Censo Demográfico 2010. Com a não realização do Censo previsto para 2020, as informações fundamentais para políticas públicas estão defasadas. Este artigo traz reflexões sobre a configuração dos quesitos do próximo Censo, ainda sem data definida. 
A metodologia utilizada foi a análise discriminante e a área de estudo corresponde às áreas urbanas ${ }^{1}$ das regiões metropolitanas (RMs) de Belém, Fortaleza, Recife, Salvador, Belo Horizonte, ${ }^{2}$ Rio de Janeiro, São Paulo, Curitiba e Porto Alegre. A abordagem aplicada é predominantemente quantitativa e busca identificar convergências nas RMs selecionadas, sem aprofundamento de suas particularidades.

\section{Aglomerado subnormal}

O processo de urbanização brasileiro, ocorrido ao longo da segunda metade do século XX, foi marcado pelo crescimento acelerado das populações urbanas, pela concentração em áreas metropolitanas e pela configuração de ocupações precárias, que abrigam parte significativa da população (FARIA,1991; MARTINE; MCGRANAHAN, 2010). Esses assentamentos recebem diferentes denominações, dependendo da região do país, sendo "favela" a mais comum no Sudeste. Nas estatísticas oficiais realizadas pelo IBGE, essas áreas são classificadas como "aglomerados subnormais".

Embora esse conceito tenha sido utilizado pela primeira vez no Censo Demográfico de 1991 e sofrido algumas mudanças em 2000 e 2010 (IBGE, 1991, 2000, 2011a), seus principais elementos (tamanho mínimo, ocupação ilegal, urbanização fora dos padrões e carência de serviços públicos essenciais) tiveram suas origens no conceito de favela empregado pelo IBGE no Recenseamento Geral de 1950 (IBGE, 1953).

Os assentamentos precários podem ter características distintas quanto à morfologia (PEDRO; QUEIROZ, 2019) e apresentar aspectos de reconfiguração ao longo do tempo, estabelecendo novas formas de precariedade (MARQUES; SARAIVA, 2017). Segundo a UN-HABITAT (2003b), slum é uma área que combina, em diferentes níveis, as seguintes características: acesso inadequado à água potável; acesso inadequado ao saneamento e outras infraestruturas; baixa qualidade estrutural da habitação; superlotação; e insegurança da posse da moradia. A possibilidade de combinação dessas características torna tal definição mais abrangente do que o conceito de aglomerado subnormal.

A exigência da ocupação ilegal do terreno no conceito de "subnormalidade" restringe a análise dos diferentes níveis de precariedade, que podem se sobrepor, ou se configurar como específicos, mas que, a partir de uma observação mais criteriosa, se estendem de maneira significativa nas metrópoles brasileiras. A seguir, são apresentadas algumas considerações acerca da categoria aglomerado subnormal e de seus atributos.

Similarmente às associações negativas relacionadas ao termo slum (GILBERT, 2007), a denominação "subnormal” carrega um sentido pejorativo, recaindo sobre a população dessas áreas o estigma de anomalia social. Esse adjetivo também sugere que as demais

\footnotetext{
${ }^{1}$ Os setores censitários de aglomerados subnormais e os setores censitários comuns em áreas urbanas, incluindo os denominados "rurais de extensão urbana" (IBGE, 2011c).

${ }^{2}$ Composta pelos municípios oficialmente pertencentes à RM de Belo Horizonte mais os municípios do colar metropolitano, em 2010.
} 
áreas das cidades são atendidas satisfatoriamente por serviços públicos essenciais, o que não é verdadeiro, como será mostrado.

Sem mencionar diretamente a categoria aglomerado subnormal, mas referindo-se às favelas como áreas de ocupação ilegal, Cardoso (2008) e Gonçalves (2013) discorreram sobre a relativa indistinção, em termos de infraestrutura urbana, entre favelas e outras áreas das cidades consideradas regulares. Segundo Gonçalves (2013), isso se deve, em parte, ao resultado alcançado com a implementação de políticas de urbanização de favelas a partir da década de 1980, que ampliaram o acesso a serviços públicos essenciais nesses locais.

Na esfera jurídica, Gonçalves (2013) apontou que o IBGE estaria mais interessado no histórico de ocupação ilegal do solo do que na condição atual de regularidade dos assentamentos, uma vez que inclui na categoria aglomerado subnormal conjuntos de habitações que passaram por algum programa de regularização fundiária.

Rolnik (2015, p. 175) defende que a categoria "ilegal", relativa aos assentamentos populares, não pode ser "absolutizada”, pois é comum encontrar modos de posse que podem ser considerados "paralegais, semilegais ou quase legais, tolerados ou legitimados por leis costumeiras ou pelo simples uso ou tradição, reconhecidos ou simplesmente ignorados pelas autoridades". A autora ainda pontua o uso político-eleitoral do reconhecimento legal desses assentamentos como mecanismo de controle da cidade pelas elites e de manutenção de mandatos políticos.

Em 2019, durante o Censo Experimental, o IBGE apresentou uma nova formulação para "subnormalidade", em que ficam evidentes a tendência de valorização da propriedade e a redução da importância dos serviços públicos essenciais (IBGE, 2019a), ao converter a ocupação ilegal na única condição obrigatória para classificar um setor censitário como subnormal. Essa definição e outras mudanças previstas para o próximo recenseamento serão abordadas no final do artigo.

\section{Metodologia}

A fim de avaliar se o conceito de aglomerado subnormal, cuja área é formada por um ou mais setores censitários classificados como subnormais, foi suficiente para representar as áreas urbanas com características socioeconômicas, demográficas, habitacionais e de infraestrutura urbana mais desfavoráveis, nas RMs selecionadas, utilizou-se a técnica estatística de análise discriminante. Essa ferramenta consiste na construção de um modelo de classificação de grupos com base em um conjunto de variáveis, de modo que a probabilidade de se classificar uma unidade de investigação (setor censitário) no grupo errado seja minimizada. Neste estudo, a variável dependente foi formada pelos grupos de setores subnormais (1) e comuns (0) e as variáveis independentes por um conjunto de 21 variáveis. Assim, os setores originalmente classificados como comuns (0), mas identificados, pela função discriminante, como subnormais (1) foram denominados setores similares. Portanto, esses setores possuíam características socioeconômicas, demográficas, habitacionais 
e de infraestrutura urbana similares às dos setores originalmente classificados como subnormais.

Devido à diversidade de situações urbanas no país, optou-se por aplicar a técnica separadamente nas RMs selecionadas. Em razão da interdependência econômica, demográfica e territorial dos municípios que compõem um espaço urbano metropolitano (IBGE, 2011b), considerou-se, para os objetivos deste estudo, cada RM como um único espaço urbano. Essa prerrogativa implica que as características dos setores similares podem variar entre as RMs, de acordo com a variação das características dos respectivos setores subnormais, e que os setores pertencentes a realidades político-administrativas distintas, dentro de uma mesma RM, podem ser diretamente comparados.

0 conjunto de 21 variáveis foi obtido a partir das informações dos domicílios particulares permanentes ${ }^{3}$ e de seus moradores, coletadas pelo questionário do universo do Censo 2010. Para a tomada de decisões sobre a inclusão das variáveis nos modelos, foram utilizados testes de igualdade de médias, as matrizes de correlações combinadas, o método de seleção de variáveis stepwise 4 e a análise da adequação dos sinais dos coeficientes estimados em relação aos resultados das análises descritivas das variáveis. 0 Quadro 1 apresenta o conjunto das 21 variáveis selecionadas.

QUADRO 1

Variáveis independentes selecionadas

\begin{tabular}{|c|c|}
\hline Dimensão & Variáveis \\
\hline \multirow{9}{*}{$\begin{array}{l}\text { Características } \\
\text { do domicílio }\end{array}$} & $\begin{array}{l}1 \text { - Porcentagem de domicílios em outra condição de ocupação (não são próprios, } \\
\text { alugados, ou cedidos) (OUT.OCUP.) }\end{array}$ \\
\hline & 2 - Porcentagem de domicílios sem ligação à rede de abastecimento de água (INAD.ÁGUA) \\
\hline & 3 - Porcentagem de domicílios sem ligação à rede de esgoto ou fossa séptica (INAD.ESG.) \\
\hline & $\begin{array}{l}4 \text { - Porcentagem de domicílios sem banheiro de uso exclusivo dos moradores e nem } \\
\text { sanitário (SEM-BANH.) }\end{array}$ \\
\hline & 5 - Número médio de banheiros por morador (BANH.MOR.) \\
\hline & 6 - Porcentagem de domicílios sem coleta de lixo (INAD.LIXO) \\
\hline & $\begin{array}{l}7 \text { - Porcentagem de domicílios com coleta de lixo em caçamba de serviço de limpeza (LIXO- } \\
\text { CAÇAM.) }\end{array}$ \\
\hline & $\begin{array}{l}8 \text { - Porcentagem de domicílios sem energia elétrica, com energia elétrica de outra fonte, } \\
\text { com energia elétrica de companhia distribuidora sem medidor ou com medidor de uso } \\
\text { coletivo (INAD.ENERG.) }\end{array}$ \\
\hline & 9 - Porcentagem de domicílios próprios e quitados (PRÓP.QUIT.) \\
\hline \multirow{6}{*}{$\begin{array}{l}\text { Características } \\
\text { do responsável } \\
\text { pelo domicílio }\end{array}$} & 10 - Porcentagem de responsáveis não alfabetizados (RESP.N.ALF.) \\
\hline & 11 - Porcentagem de responsáveis com menos de 30 anos (RESP.८30) \\
\hline & $\begin{array}{l}12 \text { - Porcentagem de responsáveis não alfabetizados com menos de } 30 \text { anos } \\
\text { (RESP.N.ALF.<30) }\end{array}$ \\
\hline & 13 - Renda média dos responsáveis pelos domicílios (RENDA-MÉD) \\
\hline & 14 - Porcentagem de responsáveis com renda de até dois salários mínimos (RENDA-2SM) \\
\hline & 15 - Porcentagem de responsáveis do sexo feminino (RESP.FEM.) \\
\hline
\end{tabular}

(Continua)

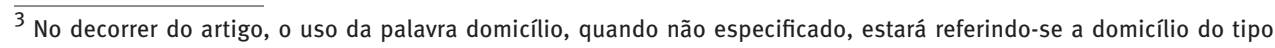
particular permanente.

${ }^{4}$ Foi utilizado o valor de $F$ como critério de inclusão ( $F$ > 3,84) e exclusão $(F<2,71)$ de variáveis nos modelos.
} 
(Continuação)

\begin{tabular}{|c|c|}
\hline Aspectos gerais & $\begin{array}{l}16 \text { - Total de domicílios particulares permanentes no setor censitário (DOM.P.P.) } \\
17 \text { - Total de pessoas residentes no setor censitário (PES.D.P.P.) } \\
18 \text { - Número médio de moradores por domicílio (MOR.DOM.) } \\
19 \text { - Total de domicílios particulares improvisados (DOM.IMP.) } \\
20 \text { - Porcentagem de pessoas residentes no setor censitário de cor/raça preta ou parda } \\
\text { (PRET.PARD.) } \\
21 \text { - Porcentagem de pessoas residentes de até dez anos que não tinham, ou não sabiam } \\
\text { se tinham, registro de nascimento (SEM-R.N.) }\end{array}$ \\
\hline
\end{tabular}

Fonte: IBGE. Censo Demográfico 2010.

As variáveis de inadequação dos serviços básicos de infraestrutura urbana foram baseadas no conceito de adequação desses serviços proposto pelo IBGE (2011b). Segundo o IBGE (2010b), o critério utilizado para a adequação dos serviços de saneamento básico resultou de uma adaptação das medidas de monitoramento da meta 11 dos Objetivos de Desenvolvimento do Milênio, propostas pela UN-HABITAT (2003a), ao contexto socioeconômico do país e à disponibilidade de informações.

Destaca-se que o IBGE participou, em 2008, da redação do documento Principles and recommendations for population and housing censuses: revision 2, organizado pelas Nações Unidas. Além da preocupação em seguir as recomendações internacionais, durante o planejamento do Censo 2010, o IBGE realizou consultas aos usuários do censo, revisou os tópicos investigados tradicionalmente, reavaliou a necessidade de manter séries históricas e avaliou a possibilidade de coletar novos dados, o que resultou, por exemplo, na inclusão do quesito sobre o uso de medidor e disponibilidade de energia elétrica (IBGE, 2010a).

Para avaliar o ajuste dos modelos, utilizaram-se os respectivos $\mathrm{R}^{2}$ canônicos, que refletem os percentuais da variância da variável dependente explicados pelas funções discriminantes. Também considerou-se o percentual de setores censitários classificados corretamente pelos modelos, em especial o percentual de classificação correta dos setores subnormais (MÁRIO, 2009; MALHOTRA, 2012).

Os valores de $\mathrm{R}^{2}$ canônico apontaram que os modelos das RMs do Norte e Sudeste (entre $37,4 \%$ e $39,8 \%$ ) se ajustaram melhor aos dados comparados aos modelos das RMs do Sul (entre $22,0 \%$ e $28,0 \%$ ), de Recife (24,0\%) e Salvador (22,0\%), os quais apresentaram ajustes melhores do que o da RM de Fortaleza (13,9\%).

Quanto aos percentuais de classificação correta de setores subnormais, a RM de Belém exibiu o melhor resultado ( $89,7 \%$ ) e a RM de Curitiba o pior $(56,1 \%)$, enquanto as demais tiveram um percentual entre $73 \%$ e $82 \%$. A RM de Belém possuía a maior proporção de setores subnormais $(51,6 \%$ ) e de Curitiba a segunda menor proporção $(5,9 \%)$, além de ter o menor número absoluto de setores desse tipo (255). Esses fatores podem ter influenciado a qualidade da classificação dos respectivos modelos.

Em seguida, elaborou-se um critério para ordenar as variáveis independentes segundo sua relevância para discriminar os setores subnormais dos comuns, em 2010, para o conjunto das RMs analisadas. Para isso, foram utilizados, simultaneamente, o valor absoluto 
das somas das correlações estruturais e o dos coeficientes padronizados das variáveis presentes nos modelos (CATALÁ, 2020; MALHOTRA, 2012). Os números absolutos e relativos de setores similares identificados, bem como de setores subnormais e comuns, por RM, serão apresentados em uma tabela, com as respectivas quantidades de domicílios e pessoas. Já para a análise da distribuição espacial dos diferentes tipos de setores, utilizaram-se mapas categóricos.

Posteriormente, relacionou-se a classificação dos setores (similares, subnormais e comuns) à adequação dos serviços de abastecimento de água, esgotamento sanitário, coleta de lixo e energia elétrica nos domicílios desses setores. Para isso, foi construída uma variável para contabilizar o número de serviços inadequados nos setores. Cada serviço foi considerado inadequado quando menos de $95 \%$ dos domicílios do setor eram atendidos adequadamente. Embora essa proporção possa ocultar informações relevantes quanto à variabilidade das condições de inadequação dentro dos setores, optou-se por esse valor por considerar que a prestação adequada dos serviços deve ser universal. 0 uso de mapas coropléticos possibilitou a análise da intensidade da inadequação dos serviços essenciais em cada grupo de setores, nas RMs analisadas.

Finalmente, encerra-se o artigo com uma reflexão sobre os impactos que as mudanças previstas nos questionários do próximo Censo Demográfico poderão ter sobre a análise das condições de vida urbana no país.

\section{Principais resultados}

Aspectos gerais dos setores subnormais nas RMs selecionadas

Em 2010, 6\% da população brasileira (11,4 milhões de pessoas) vivia em aglomerados subnormais e estava distribuída em 3,2 milhões de domicílios (5,6\%). As nove RMs selecionadas abrigavam, no mesmo ano, 72,2\% dos domicílios em aglomerados subnormais do país. Somente as RMs de São Paulo, Rio de Janeiro e Belém respondiam por quase metade $(43,7 \%)$ dos domicílios brasileiros em aglomerados subnormais.

A RM de Recife era a única com aglomerados subnormais em todos os municípios. As RMs de Belo Horizonte e Curitiba tinham as menores proporções de municípios com aglomerados subnormais, menos de um terço do total.

Quanto à proporção de domicílios em setores subnormais, as maiores porcentagens pertenciam às RMs de Belém (52,5\%), Salvador (25,7\%) e Recife $(22,4 \%)$. Os menores valores estavam nas RMs do Sul (5,2\% e 5,3\%, respectivamente, nas RMs de Curitiba e Porto Alegre).

No que se refere à distribuição dos domicílios em setores subnormais no tecido metropolitano, a maioria se concentrava nos municípios-sede das RMs selecionadas, exceto na de Recife, o que se deve, em grande parte, à maior oferta de empregos e serviços nessas localidades (IBGE, 2011b). 


\section{Identificação dos setores similares}

Segundo o IBGE, existiam, em 2010, aproximadamente 2,3 milhões de domicílios $(13,3 \%)$ em setores subnormais no conjunto das nove RMs selecionadas. Foram identificados cerca de 1,9 milhão de domicílios (10,9\%) em setores similares, correspondendo, aproximadamente, a 6,5 milhões de habitantes (11,8\%) que viviam em setores com características semelhantes às dos setores subnormais, onde residiam cerca de 8,1 milhões de pessoas (14,5\%) naquele ano, conforme apresentado na Tabela 1.

A RM de Belém teve o menor acréscimo de domicílios em setores similares, proporcionalmente ao número de domicílios em setores subnormais, seguida pela RM do Rio de Janeiro. Nas RMs de Recife, Salvador, Belo Horizonte e São Paulo, a soma de domicílios em setores subnormais e similares foi quase o dobro da quantidade de domicílios no primeiro tipo de setor. Já nas RMs de Curitiba, Porto Alegre e Fortaleza, o número de domicílios nos dois tipos de setores foi maior do que o dobro da quantidade de domicílios em setores subnormais.

Esses números revelam que a categoria aglomerado subnormal não foi suficiente para representar as áreas urbanas com maior precariedade de condições socioeconômicas, demográficas, habitacionais e de infraestrutura urbana, em 2010, nas RMs investigadas. A análise das variáveis independentes e a identificação das mais relevantes para discriminar os setores subnormais dos comuns, para o conjunto das RMs analisadas, abordadas a seguir, reforçam essa conclusão.

\section{Importância das variáveis}

Utilizaram-se, simultaneamente, as correlações estruturais e os coeficientes padronizados das variáveis para avaliar quais variáveis mais contribuíram para diferenciar os setores subnormais dos comuns, em 2010. Os valores absolutos maiores, de ambas as medidas, indicam maior importância das respectivas variáveis nas funções discriminantes.

As Tabelas 2 e 3 apresentam, respectivamente, as variáveis independentes dispostas em ordem decrescente dos valores absolutos das somas das correlações estruturais e dos coeficientes padronizados dos modelos em que estiveram presentes. Embora essas somas não sejam interpretáveis, elas funcionam como uma medida da contribuição das variáveis para a discriminação dos setores subnormais e comuns, para o conjunto das RMs analisadas. 


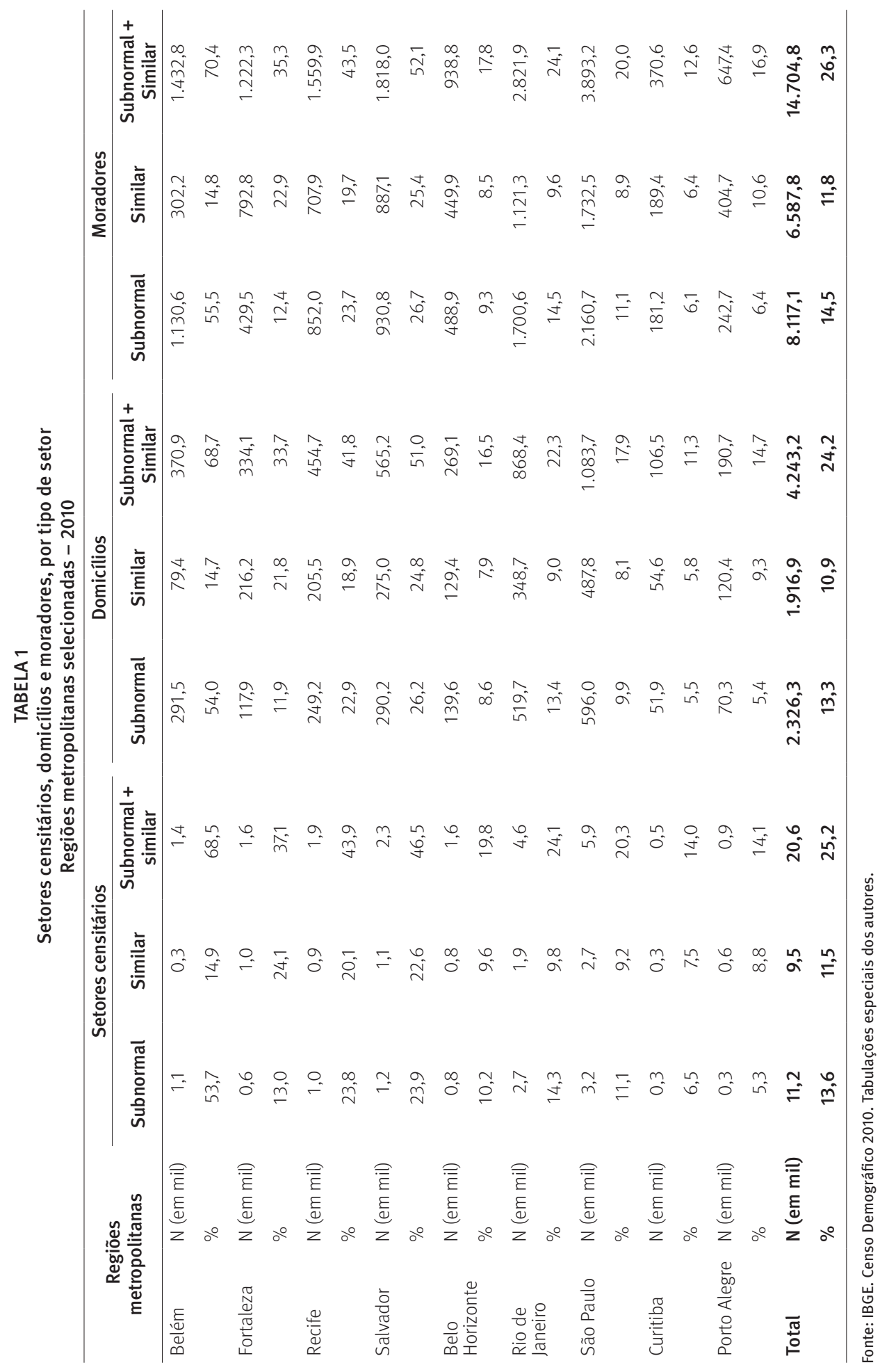


Catalá, L.S. e Carmo, R.L. O conceito de aglomerado subnormal do IBGE e a precariedade dos serviços básicos...

TABELA 2

Correlações estruturais das variáveis dos modelos de análise discriminante Regiões metropolitanas selecionadas - 2010

\begin{tabular}{|c|c|c|c|c|c|c|c|c|c|c|}
\hline Variáveis & RMB & RMF & RMR & RMS & RMBH & RMRJ & RMSP & RMPA & RMC & Soma \\
\hline INAD.ENERG. & 0,400 & 0,337 & 0,790 & 0,381 & 0,709 & 0,626 & 0,503 & 0,838 & 0,599 & 5,182 \\
\hline RESP.N.ALF. & & 0,549 & 0,753 & & 0,674 & 0,557 & 0,725 & 0,606 & 0,634 & 4,498 \\
\hline PRÓP.QUIT. & 0,510 & 0,460 & 0,461 & 0,423 & 0,424 & 0,208 & 0,241 & 0,347 & & 3,074 \\
\hline RENDA-2SM & 0,976 & 0,620 & & 0,776 & & 0,496 & & & & 2,868 \\
\hline RESP. $<30$ & & & 0,629 & 0,364 & 0,317 & 0,581 & 0,403 & 0,393 & & 2,687 \\
\hline PRET.PARD. & & & 0,700 & & & & 0,587 & 0,706 & 0,559 & 2,552 \\
\hline LIXO-CAÇAM. & & & & 0,550 & 0,331 & 0,539 & 0,396 & & & 1,816 \\
\hline RESP.N.ALF..<30 & & 0,434 & & 0,228 & & & 0,364 & 0,359 & & 1,385 \\
\hline MOR.DOM. & 0,452 & & & & & 0,364 & & & 0,473 & 1,290 \\
\hline OUT.OCUP. & & 0,134 & & & & 0,066 & 0,325 & & 0,758 & 1,283 \\
\hline RESP.FEM. & & 0,244 & & & 0,165 & & 0,112 & 0,158 & & 0,679 \\
\hline INAD.ÁGUA & & $-0,177$ & $-0,077$ & $-0,081$ & $-0,059$ & $-0,100$ & & $-0,129$ & & $-0,624$ \\
\hline SEM-BANH. & & & & & & & & 0,426 & & 0,426 \\
\hline INAD.ESG. & & $-0,084$ & & $-0,047$ & & & 0,502 & & & 0,371 \\
\hline DOM.P.P. & & $-0,216$ & $-0,122$ & 0,174 & & $-0,068$ & $-0,095$ & & & $-0,326$ \\
\hline PES.D.P.P. & & & & & $-0,102$ & & & & $-0,070$ & $-0,171$ \\
\hline INAD.LIXO & & & & 0,142 & & & & & & 0,142 \\
\hline
\end{tabular}

Fonte: IBGE. Censo Demográfico 2010. Tabulações especiais dos autores.

TABELA 3

Coeficientes padronizados das variáveis dos modelos de análise discriminante

Regiões metropolitanas selecionadas - 2010

\begin{tabular}{|c|c|c|c|c|c|c|c|c|c|c|}
\hline Variáveis & RMB & RMF & RMR & RMS & RMBH & RMRJ & RMSP & RMPA & RMC & Soma \\
\hline INAD.ENERG. & 0,141 & 0,285 & 0,472 & 0,205 & 0,546 & 0,308 & 0,071 & 0,536 & 0,212 & 2,777 \\
\hline RESP.N.ALF. & & 0,454 & 0,243 & & 0,457 & 0,339 & 0,418 & 0,180 & 0,355 & 2,447 \\
\hline PRÓP.QUIT. & 0,122 & 0,242 & 0,223 & 0,234 & 0,272 & 0,140 & 0,457 & 0,234 & & 1,923 \\
\hline RENDA-2SM & 0,857 & 0,391 & & 0,590 & & 0,049 & & & & 1,887 \\
\hline INAD.ÁGUA & & $-0,447$ & $-0,117$ & $-0,204$ & $-0,346$ & $-0,413$ & & $-0,233$ & & $-1,761$ \\
\hline LIXO-CAÇAM. & & & & 0,431 & 0,267 & 0,497 & 0,324 & & & 1,519 \\
\hline RESP.<30 & & & 0,314 & 0,117 & 0,092 & 0,366 & 0,196 & 0,179 & & 1,264 \\
\hline OUT.OCUP. & & 0,130 & & & & 0,047 & 0,336 & & 0,677 & 1,190 \\
\hline PRET.PARD. & & & 0,171 & & & & 0,206 & 0,254 & 0,126 & 0,757 \\
\hline INAD.ESG. & & $-0,509$ & & $-0,371$ & & & 0,154 & & & $-0,725$ \\
\hline RESP.FEM. & & 0,154 & & & 0,169 & & 0,093 & 0,095 & & 0,511 \\
\hline DOM.P.P. & & $-0,286$ & $-0,134$ & 0,068 & & & $-0,180$ & $-0,132$ & & $-0,401$ \\
\hline PES.D.P.P. & & & & & $-0,237$ & & & & $-0,131$ & $-0,367$ \\
\hline RESP.N.ALF.<30 & & 0,143 & & 0,117 & & & 0,023 & 0,060 & & 0,342 \\
\hline MOR.DOM. & 0,100 & & & & & 0,084 & & & 0,116 & 0,300 \\
\hline SEM-BANH. & & & & & & & & 0,105 & & 0,105 \\
\hline INAD.LIXO & & & & 0,093 & & & & & & 0,093 \\
\hline
\end{tabular}

Fonte: IBGE. Censo Demográfico 2010. Tabulações especiais dos autores. 
As quatro primeiras variáveis das duas tabelas, em negrito, coincidiram, sugerindo que as variáveis INAD.ENERG., RESP.N.ALF., PRÓP.QUIT. e RENDA-2SM foram as mais relevantes para diferenciar os setores subnormais dos comuns, em 2010, no conjunto das RMs analisadas. A relação dessas variáveis com a variável resposta foi positiva em todos os modelos, o que significa que um aumento dessas porcentagens resultaria em um incremento da probabilidade de um setor ser classificado como subnormal, naquele ano.

A INAD.ENERG. foi a única variável presente em todos os modelos e, sob o critério utilizado, foi a que mais discriminou os setores subnormais dos comuns no conjunto das RMs analisadas. Nos modelos das RMs de Belo Horizonte, Porto Alegre e Recife, essa foi a variável mais relevante.

O Gráfico 1, com a caracterização dos setores censitários segundo o percentual de domicílios com fornecimento inadequado de energia elétrica, ilustra como os setores similares eram, sob esse aspecto, mais parecidos com os setores subnormais do que com os comuns nas RMs selecionadas.

\section{GRÁFICO 1}

Domicílios com fornecimento inadequado de energia elétrica, por tipo de setor Regiões metropolitanas selecionadas - 2010

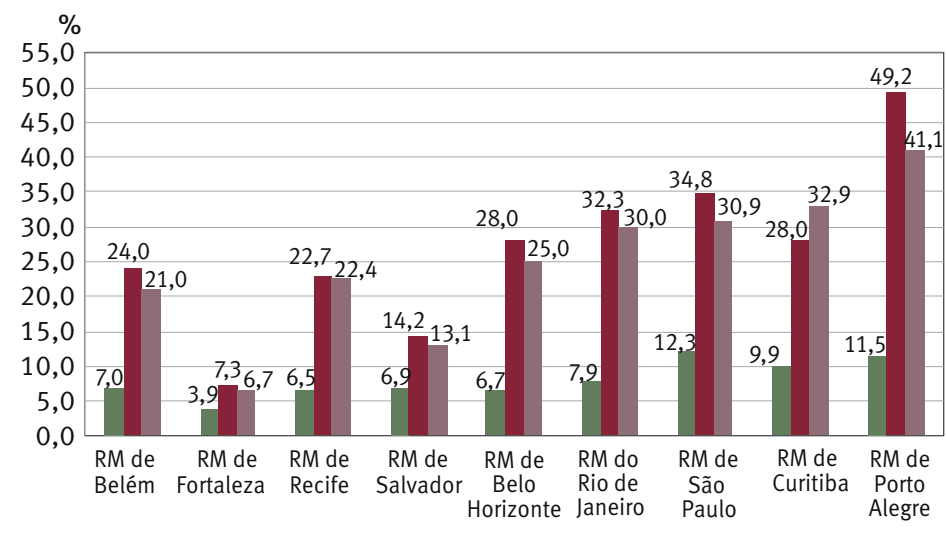

Setores comuns Setores subnormais Setores similares

Fonte: IBGE. Censo Demográfico 2010. Tabulações especiais dos autores.

A variável RESP.N.ALF. esteve em sete modelos, sendo que nos modelos das RMs de Fortaleza, Belo Horizonte, São Paulo e Curitiba situou-se entre as duas variáveis mais importantes. 0 Gráfico 2 mostra o percentual de responsáveis não alfabetizados nas RMs analisadas, por tipo de setor, evidenciando a semelhança entre os setores subnormais e similares, quanto a essa questão. 


\section{GRÁFICO 2}

Responsáveis por domicílios não alfabetizados, por tipo de setor

Regiões metropolitanas selecionadas - 2010

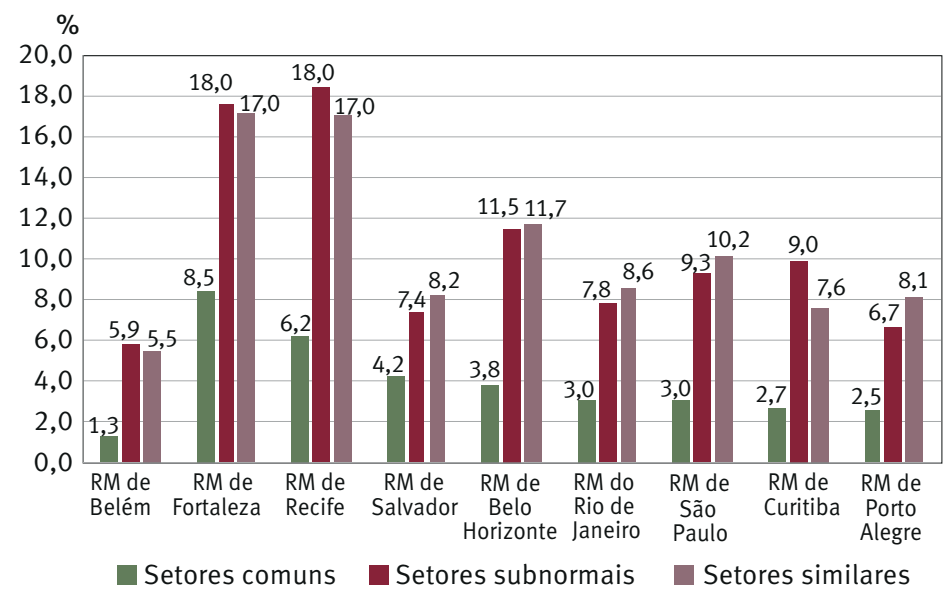

Fonte: IBGE. Censo Demográfico 2010. Tabulações especiais dos autores.

Quanto à variável PRÓP.QUIT., ela esteve presente em oito modelos, reforçando o argumento de que a ocupação ilegal de terras urbanas é a principal forma de uma parcela da população suprir sua necessidade por moradia a baixo custo. 0 Gráfico 3 ilustra a similitude entre os setores subnormais e similares nas RMs investigadas, em relação a esse quesito.

GRÁFICO 3

Domicílios próprios ou quitados, por tipo de setor

Regiões metropolitanas selecionadas - 2010

$\%$

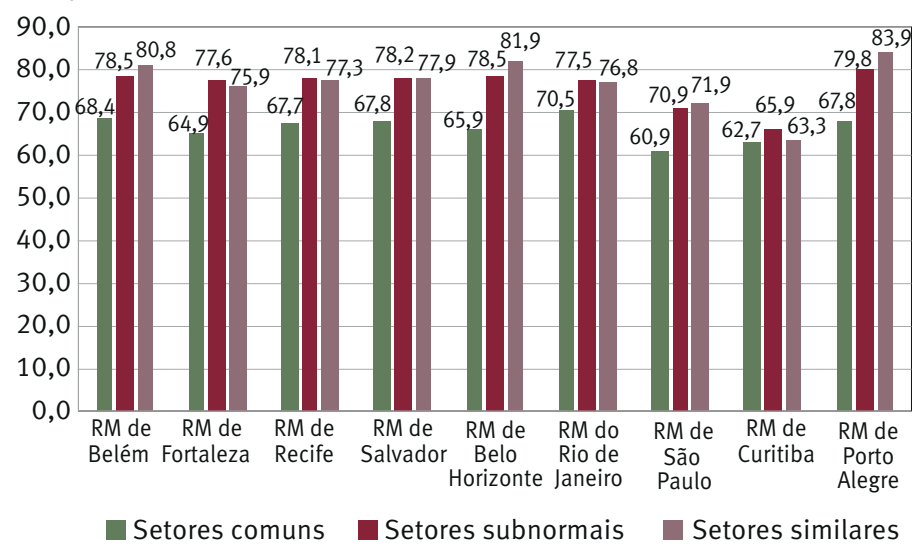

Fonte: IBGE. Censo Demográfico 2010. Tabulações especiais dos autores.

Apesar de a RENDA-2SM compor apenas quatro modelos, essa variável foi considerada a mais importante nas RMs de Belém e Salvador, sendo que, na primeira, as magnitudes da correlação estrutural e do coeficiente padronizado foram as mais altas de todas as variáveis, 
em todos os modelos. 0 Gráfico 4 mostra o quão próximos eram os setores subnormais dos similares, quanto a essa medida, nas RMs analisadas.

\section{GRÁFICO 4}

Responsáveis por domicílios com renda de até dois salários mínimos, por tipo de setor

Regiões metropolitanas selecionadas - 2010

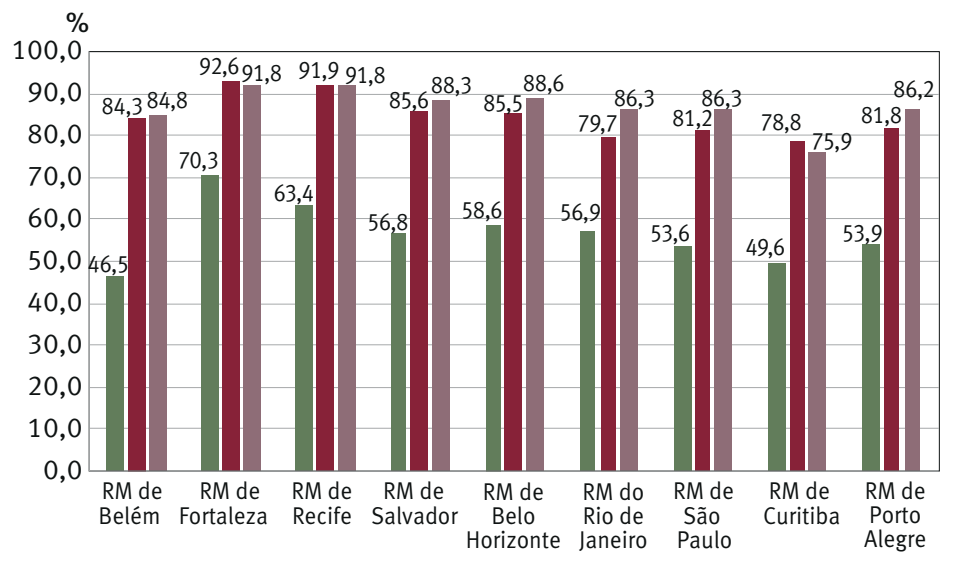

Setores comuns $\square$ Setores subnormais $\quad$ Setores similares

Fonte: IBGE. Censo Demográfico 2010. Tabulações especiais dos autores.

A posição da variável INAD.LIXO em último lugar nas Tabelas 2 e 3, em negrito, presente apenas no modelo da RM de Salvador, mostrou que a alta cobertura do serviço de coleta de lixo nas RMs analisadas, em 2010, tornou seu poder discriminativo bastante reduzido. No entanto, a variável que especifica a coleta realizada em caçamba de serviço de limpeza, LIXO-CAÇAMB., presente em quatro modelos, revela que a forma como o lixo era coletado é mais relevante para diferenciar os setores subnormais dos comuns.

Sobre o serviço de abastecimento de água, observou-se uma associação negativa entre a variável INAD.ÁGUA e a classificação dos setores subnormais: exceto nas RMs de Belém, São Paulo e Curitiba, pode-se dizer que, segundo os modelos, a classificação de um setor censitário como subnormal dependia de uma menor proporção de domicílios com serviço de abastecimento de água inadequado, quando comparada à mesma proporção nos setores comuns das RMs.

Uma interpretação semelhante se aplica à variável INAD.ESG. nas RMs de Fortaleza e Salvador, onde uma redução na proporção de domicílios com serviço inadequado aumentava a chance de um setor ser classificado como subnormal, mantidas fixas as demais variáveis dos modelos. Em contrapartida, na RM de São Paulo, a correlação estrutural e o coeficiente padronizado dessa variável apresentaram sinais positivos (em negrito nas Tabelas 2 e 3), expressando uma maior inadequação do serviço de esgotamento sanitário entre os domicílios dos setores subnormais.

Os resultados contraintuitivos sobre a inadequação dos serviços de água e esgoto em setores subnormais, em algumas RMs, podem estar relacionados à diversidade de 
configurações das redes urbanas metropolitanas brasileiras e à construção de um único modelo para o conjunto de setores de uma RM, o que levou à comparação direta entre setores subnormais, geralmente localizados em "municípios mais ricos e estruturados", e setores comuns de municípios sem setores subnormais, onde "muitas vezes predominavam áreas mais pobres e com infraestrutura mais precária” (IBGE, 2011b, p. 47).

\section{Distribuição espacial dos setores}

Neste artigo, optou-se por apresentar os mapas temáticos categorizados com a distribuição espacial dos setores similares identificados, bem como dos demais setores, das RMs de Belém e São Paulo, por serem aquelas com maior proporção e volume de domicílios em setores subnormais, respectivamente, em 2010. Esses resultados estão nos Mapas 1 e 2.

MAPA 1

Distribuição espacial dos setores censitários, segundo tipo de setor Região metropolitana de Belém - 2010

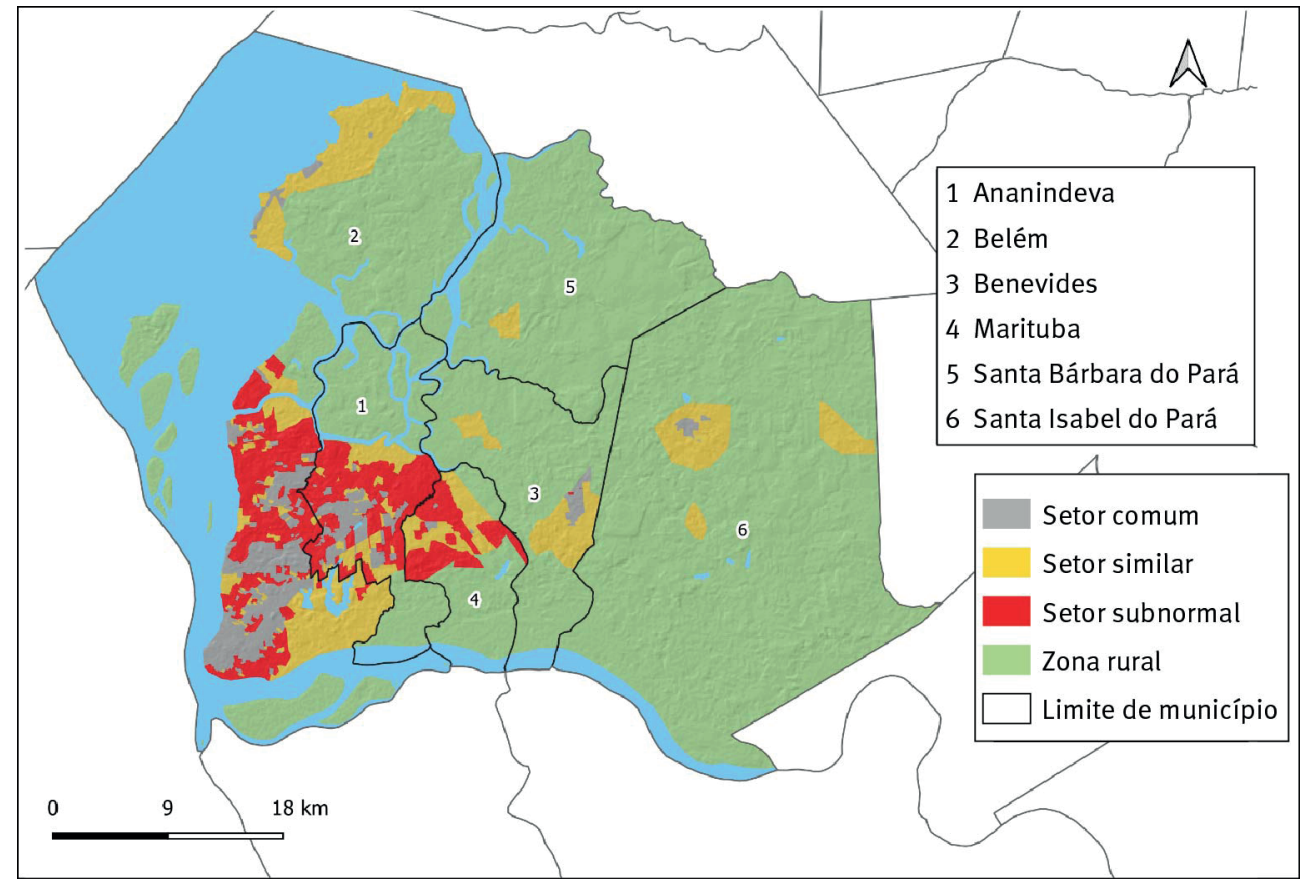

Fonte: IBGE. Censo Demográfico 2010. Tabulações especiais dos autores.

Na RM de Belém, os municípios de Belém, Ananindeua e Marituba reuniam 92,6\% da população residente em setores subnormais e $79,9 \%$ da população em setores similares. Quanto aos municípios de menor porte populacional, Santa Bárbara do Pará e Santa Izabel do Pará, que não apesentavam setores subnormais identificados em 2010, tiveram, respectivamente, $100 \%$ e $80,5 \%$ dos setores classificados como similares. Em Benevides, onde 
apenas $2,4 \%$ da população vivia em setores subnormais, segundo o IBGE, foi identificado que $85,2 \%$ da população residia em setores similares.

\section{MAPA 2}

Distribuição espacial dos setores censitários, segundo tipo de setor Região metropolitana de São Paulo - 2010

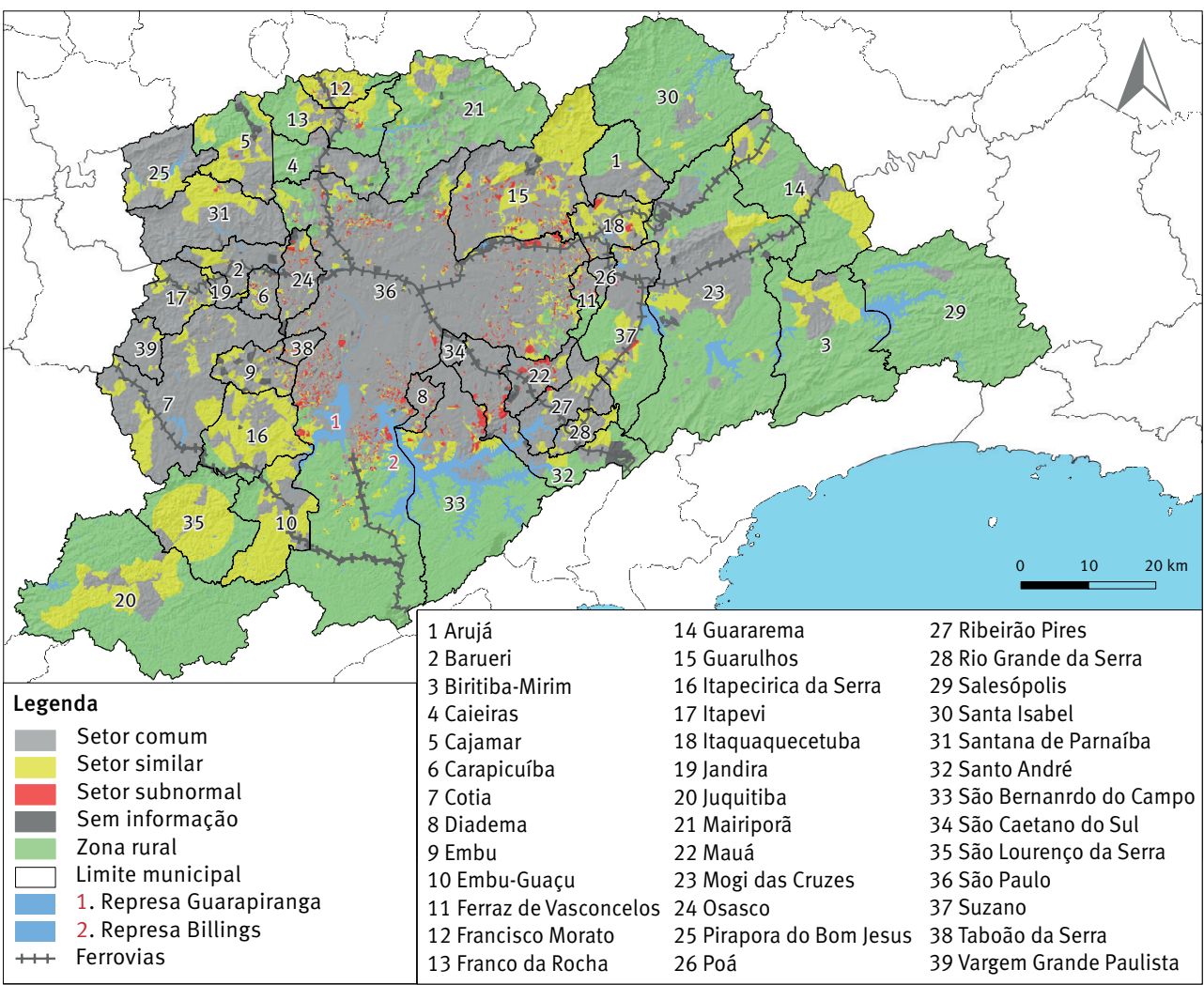

Fonte: IBGE. Censo Demográfico 2010. Tabulações especiais dos autores.

Em 2010, cerca de 11,1\% da população da RM de São Paulo vivia em setores subnormais, segundo o IBGE. Com a identificação dos setores similares, o percentual da população em condições mais desfavoráveis na RM chegou a 20\%. Dos 39 municípios que formam essa RM, 15 não apresentaram setores subnormais identificados pelo IBGE. 0 único município onde não foram identificados setores similares foi São Caetano do Sul. Destaca-se que a variável PRET.PARD. esteve entre as mais importantes no modelo dessa RM.

De modo geral, a análise dos mapas categóricos das RMs investigadas mostrou que os setores similares se encontravam mais dispersos do que os subnormais, que estavam mais concentrados nas capitais, exceto na RM de Recife. Frequentemente, os setores similares eram contíguos aos subnormais e se encontravam, principalmente, nas áreas periféricas dos municípios e das RMs como um todo. 
Enquanto $71 \%$ dos domicílios em setores subnormais das RMs analisadas estavam localizados nos municípios-sede, menos da metade dos domicílios em setores similares $(47,5 \%)$ pertenciam às capitais, sugerindo uma "periferização" das condições urbanas adversas no tecido metropolitano. Isso mostra que a classificação “subnormal”, em 2010, privilegiou, de forma geral, os municípios-sede das RMs como unidade de análise das desigualdades sociais nas áreas urbanas.

Dos 211 municípios que formavam as nove RMs analisadas, em 2010, apenas 19 , localizados nas RMs do Sudeste e Sul, não tiveram nenhum setor similar identificado, enquanto, para o IBGE, 107 municípios não possuíam precariedade habitacional e de infraestrutura urbana, naquele ano, se considerada a classificação de "subnormalidade".

\section{A "subnormalidade" e a adequação dos serviços básicos de infraestrutura urbana}

A análise da relevância das variáveis nos modelos de análise discriminante mostrou que a inadequação dos serviços de água, esgoto e coleta de lixo não estava entre os aspectos que mais diferenciavam os setores subnormais dos comuns, em 2010. Por outro lado, a inadequação do serviço de energia elétrica foi a variável mais importante para discriminar esses setores, no conjunto das RMs analisadas.

Diante disso, tornou-se importante a avaliação da relação entre a classificação dos setores e a inadequação dos serviços básicos. Para tal, foi construída uma variável (INADEQ) para contabilizar o número de serviços inadequados em cada setor, em 2010, de acordo com a seguinte definição:

- setor com inadequação do serviço de abastecimento de água: menos de 95\% dos domicílios possuíam abastecimento de água por rede geral de distribuição;

- setor com inadequação do serviço de esgotamento sanitário: menos de 95\% dos domicílios possuíam esgotamento sanitário por rede geral de esgoto ou pluvial, ou por fossa séptica;

- setor com inadequação do serviço de coleta de lixo: menos de 95\% dos domicílios possuíam lixo coletado diretamente por serviço de limpeza ou em caçamba de serviço de limpeza;

- setor com inadequação do serviço de fornecimento de energia elétrica: menos de 95\% dos domicílios possuíam energia elétrica de companhia distribuidora e medidor de uso exclusivo.

Com a variável INADEQ assumindo valores de 0 a 4, foram elaborados mapas coropléticos por tipos de setores (total, subnormais, similares e comuns), em que a tonalidade da cor vermelha se intensifica com o aumento do número de inadequações nos setores. Os Mapas 3 e 4 ilustram os resultados das RMs de Belém e São Paulo.

$\mathrm{Na}$ RM de Belém, apenas 4,7\% dos setores não possuíam inadequações, todos localizados em Belém e Ananindeua. A maioria dos setores subnormais e similares tinha mais de duas inadequações ( $52,3 \%$ e $63,4 \%$, respectivamente), ao passo que, entre os 
setores comuns, esse percentual foi de $20,9 \%$, um dos mais altos entre as RMs analisadas. O serviço de coleta de lixo foi o menos problemático na RM de Belém.

Proporcionalmente, em 2010, a RM de São Paulo era a que possuía melhores condições de infraestrutura urbana, com $79,7 \%$ dos setores com no máximo uma inadequação. Entre esses setores, 94,5\% tinham o fornecimento de energia elétrica prestado de maneira inadequada, apesar de quase a totalidade dos domicílios dessa RM $(99,9 \%)$ receber luz elétrica (IBGE, 2011a). Nessa RM, apenas $2 \%$ dos setores comuns possuíam três ou quatro inadequações, enquanto entre os setores similares esse percentual (24,0\%) era quase três vezes superior ao dos setores subnormais (8,7\%), revelando que, em certas áreas consideradas "comuns", a abrangência de serviços adequados era menor do que em áreas consideradas "subnormais" pelo IBGE.

A análise da inadequação dos serviços de infraestrutura urbana nos setores censitários das RMs investigadas mostrou que, de maneira geral, os setores comuns possuíam menor número de serviços inadequados, quando comparados aos subnormais e similares, sendo que estes apresentaram, proporcionalmente, mais serviços inadequados do que os anteriores. Por outro lado, quando analisados os resultados em termos absolutos, o número de setores comuns com três ou quatro inadequações era próximo ou superior à soma de setores subnormais e similares com o mesmo número de inadequações, exceto nas RMs de Belém, Recife e São Paulo.

\section{MAPA 3}

Distribuição espacial dos setores, por número de inadequações de serviços, segundo tipo de setor Região metropolitana de Belém - 2010

Total

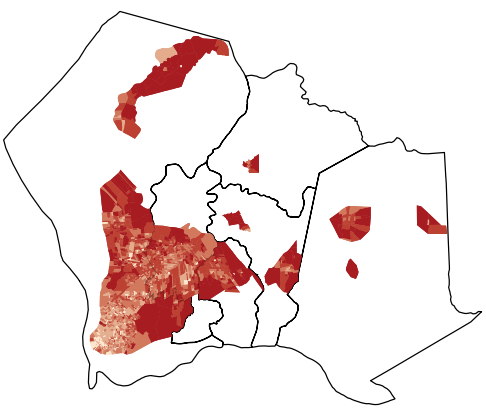

Similar

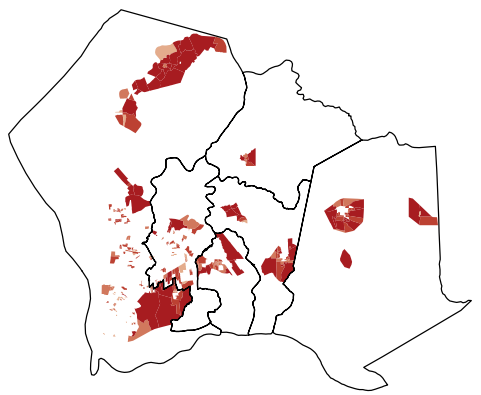

\section{Subnormal}

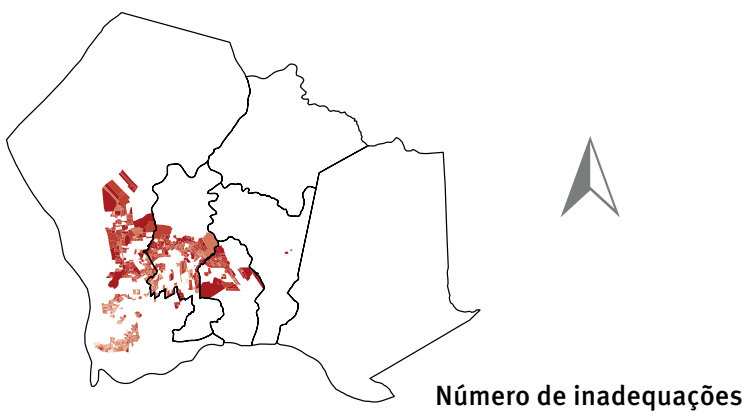

Comum

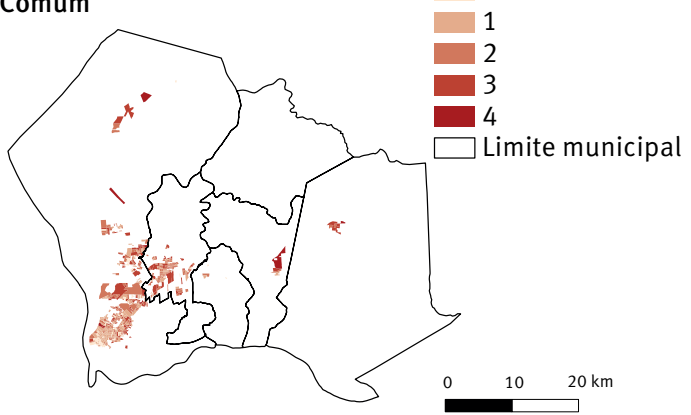

Fonte: IBGE. Censo Demográfico 2010. Tabulações especiais dos autores. 
MAPA 4

Distribuição espacial dos setores, por número de inadequações de serviços, segundo tipo de setor Região metropolitana de São Paulo - 2010
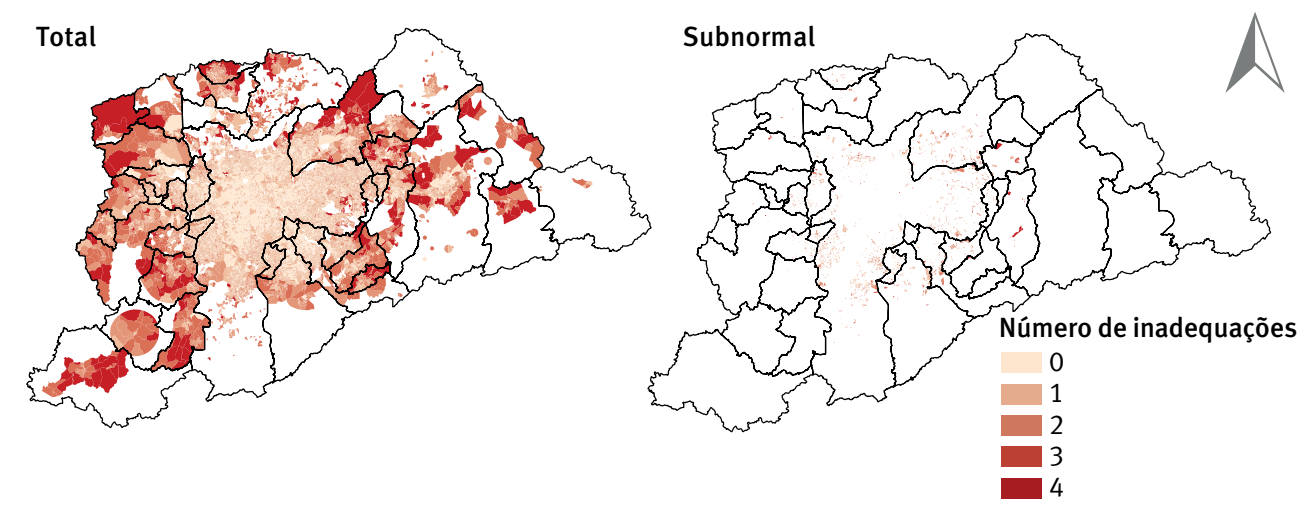

Similar
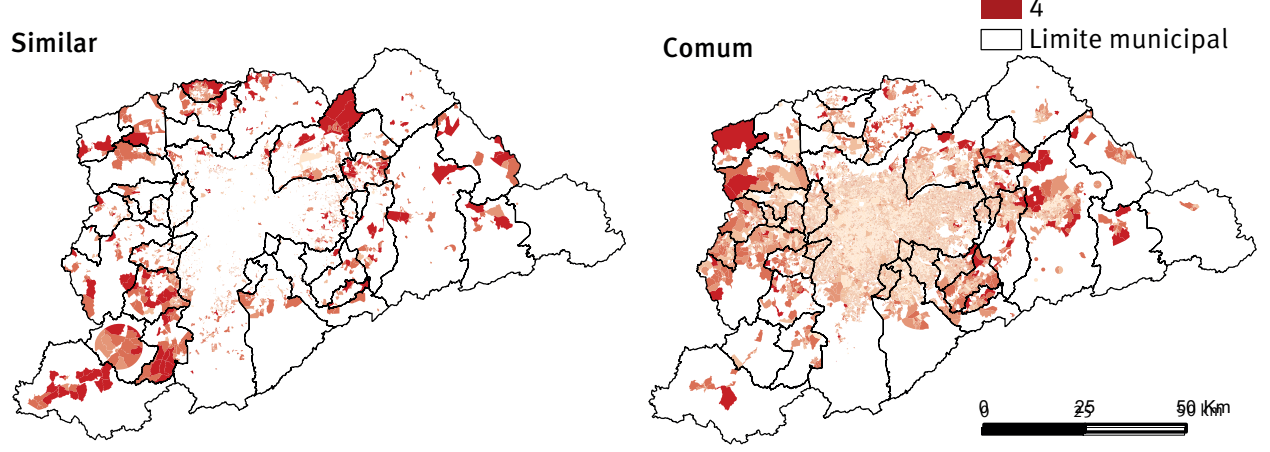

Fonte: IBGE. Censo Demográfico 2010. Tabulações especiais dos autores.

Destaca-se que, em quaisquer dos subconjuntos de setores, havia, proporcionalmente, mais setores com três ou quatro inadequações fora das capitais do que nelas. Além do acúmulo histórico da prevalência de investimentos nas áreas centrais das principais cidades brasileiras e do descompasso entre a expansão urbana na segunda metade do século passado e a disponibilização de serviços básicos de infraestrutura urbana (FERREIRA, 2005), é provável que a concentração de investimentos do Programa de Aceleração do Crescimento (PAC) nas grandes cidades, durante a década de 2000 , tenha contribuído para essa configuração (CARDOSO; DENALDI, 2018). Com a continuidade de obras de infraestrutura resultantes desse programa após 2010, é possível que essa desigualdade se mostre ainda mais acentuada no próximo recenseamento.

\section{Conclusão}

A classificação de "subnormalidade" do IBGE não foi suficiente para representar as áreas urbanas com maior demanda de serviços básicos de infraestrutura urbana ou mesmo de adequação desses serviços nas RMs analisadas, em 2010. Ribeiro e Ribeiro (2016) mostraram que, no mesmo ano, mais da metade dos municípios brasileiros apresentavam 
condições ruins (47\%) ou muito ruins (7\%) relativas à adequação dos mesmos serviços tratados neste estudo, ao passo que, para o IBGE, apenas 323 municípios brasileiros possuíam aglomerados subnormais (IBGE, 2011b).

Foi possível perceber que a localização urbana, determinante para a produção social do espaço e constantemente articulada pelos interesses da especulação imobiliária, cuja valorização depende, entre outras coisas, da rede de infraestrutura urbana disponível (VILLAÇA, 2001), dizia mais sobre a precariedade dos serviços essenciais do que a condição de "subnormalidade" utilizada pelo IBGE.

\section{Mudanças previstas para o próximo Censo Demográfico}

Durante a pesquisa-piloto para o Censo Demográfico 2020, realizada em 2019, o IBGE apresentou uma nova formulação para a classificação de “subnormalidade”, em que fica evidente a tendência de valorização da propriedade e de redução da importância dos serviços públicos essenciais. Segundo o IBGE (2019a, p. 19), um setor censitário de tipo aglomerado subnormal é caracterizado como:

Forma de ocupação ilegal de terrenos de propriedade alheia (públicos ou privados) para fins de habitação em áreas urbanas e, em geral, caracterizados por um padrão urbanístico irregular, carência de serviços públicos essenciais e localização em áreas restritas à ocupação.

Nessa definição, fica evidente a primazia da ilegalidade da ocupação em detrimento da precariedade de infraestrutura urbana, pois tornam-se opcionais a irregularidade urbanística e a carência de serviços públicos essenciais, convertendo a ocupação ilegal na única condição obrigatória para caracterizar um setor como subnormal.

Embora a análise dos setores subnormais, de 2010, apontasse para isso, a reformulação apresentada escancara o que estava implícito: que a "normalidade" do espaço urbano depende, para o órgão oficial de estatísticas do país, exclusivamente da ocupação de terrenos de propriedade privada, corroborando o permanente estigma territorial dos assentamentos com histórico de ocupação ilegal.

Além disso, outras mudanças previstas para o próximo Censo Demográfico são preocupantes, como a retirada de quesitos dos questionários do universo e da amostra, sem ampla discussão com a sociedade e tampouco com a divulgação de estudos técnicos que embasem essas decisões, o que inviabilizará a formulação de determinadas políticas sociais, sobretudo no âmbito intraurbano.

Na esfera habitacional e de infraestrutura urbana, está prevista a exclusão, de ambos os questionários, dos quesitos sobre o valor do aluguel, imprescindível para o cálculo do déficit habitacional, a posse de alguns bens e a origem do fornecimento de energia elétrica (IBGE, 2019b), cuja variável de inadequação desse serviço foi considerada, no presente estudo, a mais importante para discriminar os setores subnormais dos comuns, em 2010, nas RMs analisadas. 
A condição de uso e posse do domicílio, que identifica os domicílios declarados como próprios e quitados, cuja variável esteve entre as quatro mais importantes para diferenciar os setores subnormais dos comuns nas análises apresentadas, está prevista para constar apenas no questionário da amostra (IBGE, 2019b). Outras mudanças, como a retirada da renda de todos os moradores, exceto do responsável pelo domicílio, do questionário do universo (IBGE, 2019b), poderão impactar sobremaneira o conhecimento da realidade brasileira e inviabilizar o planejamento de políticas públicas com base em evidências.

Cabe destacar que no documento Principles and recommendations for population and housing censuses: revision 2, das Nações Unidas, é reconhecida a prioridade das necessidades nacionais sobre as recomendações regionais e globais (UNITED NATIONS, 2008).

\section{Considerações finais}

No atual cenário de retrocessos e de desvalorização do conhecimento científico, é preciso que novas formas de enxergar e de retratar a população brasileira e suas condições de vida sejam formuladas e disponibilizadas. No domínio das condições habitacionais e de infraestrutura, faz-se necessário que essas abordagens tragam à tona a distribuição desigual de recursos públicos que configuram nossas cidades.

Se a ilegalidade na ocupação de terras urbanas no Brasil é um fenômeno tão complexo, fruto das bases colonialistas e patrimonialistas de nossa história, sistematicamente tolerada pelo poder público, com o acesso formal à terra restrito a uma parcela da população e a função social da propriedade ainda é um direito em disputa, questiona-se: por que o IBGE deve considerar a condição de ocupação dos terrenos como o principal aspecto para classificar um aglomerado "subnormal”, colocando em segundo plano a adequação dos serviços de infraestrutura urbana? Diante dessa questão, sinaliza-se a necessidade de o IBGE considerar a divulgação dos dados censitários intraurbanos por meio de uma classificação que expresse de maneira mais ampla as necessidades da população nos diferentes territórios urbanos, expondo as áreas das cidades mais atingidas pela desigualdade na distribuição de recursos públicos. Neste trabalho foi apresentada a possibilidade do uso de uma variável que quantifique o número de serviços inadequados nos setores censitários, mas certamente outros arranjos de dados censitários podem ser elaborados.

Ao considerar novas formas de representação da precariedade urbana ou ao menos substituir o termo "subnormal" por outro que explicite a intenção de classificar juridicamente os territórios da cidade, o IBGE contribuiria para minimizar o estigma que atribui às áreas com histórico de ocupação ilegal, pela população de baixa renda, o lugar da ilegalidade e da pobreza urbana. Além disso, essas novas abordagens podem ajudar a colocar no centro da discussão o papel dos formuladores e executores de políticas públicas, mais do que a atuação da população cujo direito constitucional à moradia adequada não é garantido. 


\section{Referências}

CAIADO, A. S. C. C. Metrópoles, cidades médias e pequenos municípios paulistas: estudo comparado da qualidade de vida e dinâmica socioespacial. In: PATARRA, N. L. (org.). Migração, condições de vida e dinâmica urbana: São Paulo 1980-1993. Campinas, SP: IE/Unicamp, 1997. p. 115-152.

CARDOSO, A. L. Assentamentos precários no Brasil: discutindo conceitos. Cadernos do CEAS Revista Crítica de Humanidades, Salvador, BA, n. 230, p. 51-80, 2008. Disponível em: https:// periodicos.ucsal.br/index.php/cadernosdoceas/article/view/102. Acesso em: 12 mar. 2019.

CARDOSO, A. L.; DENALDI, R. Balanço. In: CARDOSO, A. L.; DENALDI, R. Urbanização de favelas no Brasil: um balança preliminar do PAC. Rio de Janeiro, RJ: Letra Capital, 2018. p. 17-48.

CATALÁ, L. O retrato da realidade urbana no país onde "a terra é nó”. Dissertação (Mestrado) Programa de Pós-graduação em Demografia da Universidade Estadual de Campinas (Unicamp), Campinas, SP, 2020.

D'OTTAVIANO, C. Abrindo janelas: alternativas para a moradia no Brasil. São Paulo, SP: Universidade de São Paulo, 2019.

FARIA, V. E. Cinquenta anos de urbanização no Brasil. Tendências e perspectivas. Novos Estudos Cebrap, n. 29, p. 98-119, 1991.

FERREIRA, J. S. W. A cidade para poucos: breve história da propriedade urbana no Brasil. In: SIMPÓSIO INTERFACES DAS REPRESENTAÇÕES URBANAS EM TEMPOS DE GLOBALIZAÇÃO. Anais [...]. Bauru, SP: Unesp/Sesc-Bauru, 2005.

GARDINI, A. A demonização da habitação informal. ComCiência - Revista Eletrônica de Jornalismo Científico, Campinas, SP, n. 88, 2009.

GILBERT, A. The return of the slum: does language matter? International Journal of Urban and Regional Research, v. 31, n. 4, p. 697-713, 2007.

GONÇALVES, R. S. Favelas do Rio de Janeiro: história e direito. Rio de Janeiro, RJ: Pallas/Ed. PUC-Rio, 2013.

GONÇALVES, R. S. A política, o direito e as favelas do Rio de Janeiro: um breve olhar histórico. Urbana - Revista Eletrônica do Centro Interdisciplinar de Estudos sobre a Cidade (Ciec), Campinas, SP, v. 1, n. 1, 2006. Disponível em: https://periodicos.sbu.unicamp.br/ojs/index. php/urbana/article/view/8635115/2930.

IBGE - Instituto Brasileiro de Geografia e Estatística. As favelas do Distrito Federal e o Censo Demográfico de 1950. Documentos Censitários, Rio de Janeiro, RJ, v. C, n. 9, 1953.

IBGE - Instituto Brasileiro de Geografia e Estatística. Manual de delimitação de setores e zonas de trabalho de 1990. Rio de Janeiro, RJ, 1991.

IBGE - Instituto Brasileiro de Geografia e Estatística. Manual de delimitação dos setores: Censo Demográfico 2000. Rio de Janeiro, RJ, 2000. Disponivel em: http://biblioteca.ibge.gov.br/ visualizacao/instrumentos_de_coleta/doc0210.pdf.

IBGE - Instituto Brasileiro de Geografia e Estatística. Censo 2010: síntese das etapas da pesquisa. Rio de Janeiro, RJ, 2010a.

IBGE - Instituto Brasileiro de Geografia e Estatística. Síntese de indicadores sociais: uma análise das condições de vida da população brasileira. Rio de Janeiro, RJ, 2010 b. 
IBGE - Instituto Brasileiro de Geografia e Estatística. Censo Demográfico 2010: resultados do universo agregados por setor censitário. Rio de Janeiro, RJ, 2011a. Disponível em: https:// censo2010.ibge.gov.br/resultados.html.

IBGE - Instituto Brasileiro de Geografia e Estatística. Censo Demográfico 2010: aglomerados subnormais: primeiros resultados. Rio de Janeiro, RJ, 2011b. Disponível em: https://biblioteca. ibge.gov.br/visualizacao/periodicos/92/cd_2010_aglomerados_subnormais.pdf.

IBGE - Instituto Brasileiro de Geografia e Estatística. Base de informações do Censo Demográfico 2010: resultados do universo por setor censitário: documentação do arquivo. Rio de Janeiro, RJ, 2011C.

IBGE - Instituto Brasileiro de Geografia e Estatística. Censo Demográfico 2020: manual do recenseador. Parte 1. Rio de Janeiro, RJ, IBGE, 2019a.

IBGE - Instituto Brasileiro de Geografia e Estatística. Censo Demográfico 2020: manual do recenseador. Parte 2. Rio de Janeiro, RJ, IBGE, 2019b.

MALHOTRA, N. K. Pesquisa de marketing: uma orientação aplicada. 6. ed. Porto Alegre, RS: Bookman, 2012.

MARICATO, E. O nó da terra. Revista Piauí, edição 21, jun. 2008. Disponível em: https://piaui. folha.uol.com.br/materia/o-no-da-terra/. Acesso em: 27 jun. 2019.

MARICATO, E. As idéias fora do lugar e o lugar fora das idéias. In: ARANTES, O.; VAINER, C.; MARICATO, E. A cidade do pensamento único: desmanchando consensos. 4. ed. Petrópolis, RJ: Vozes, 2007. p. 121-192.

MARICATO, E. Urbanismo na periferia do mundo globalizado: metrópoles brasileiras. São Paulo em Perspectiva, São Paulo, SP, v. 14, n. 4, p. 21-33, 2000.

MÁRIO, P. C. Análise discriminante. In: CORRAR, L. J.; PAULO, E.; DIAS, J. M. F. (ed.). Análise multivariada para os cursos de administração, ciências contábeis e economia. São Paulo, SP: Atlas, p. 232-279, 2009.

MARQUES, E.; SARAIVA, C. Urban integration or reconfigured inequalities? Analyzing housing precarity in São Paulo, Brazil. Habitat International, v. 69, p. 18-26, 2017. DOI: https://doi. org/10.1016/j.habitatint.2017.08.004.

MARTINE, G.; MCGRANAHAN, G. Brazil's early urban transition: what can it teach urbanizing countries? IIED, 2010.

PEDRO, A. A.; QUEIROZ, A. P. Slum: comparing municipal and census basemaps. Habitat Intertational, v. 83, p. 30-40, 2019. DOI: http://doi.org/10.1016/j.habitant.2018.11.001.

RIBEIRO, L. C. Q.; RIBEIRO, M. G. R. (org.). IBEU municipal: índice de bem-estar urbano nos municípios brasileiros. Rio de Janeiro, RJ: Observatório das Metrópoles, 2016. Disponível em: http:// https://www.observatoriodasmetropoles.net.br/wp-content/uploads/2019/11/IBEUMUNICIPAL_FINAL.pdf. Acesso em: 31 jan. 2020.

ROLNIK, R. Guerra dos lugares: a colonização da terra e da moradia na era das finanças. São Paulo, SP: Boitempo, 2015.

ROLNIK, R. Para além da lei: legislação urbanística e cidadania (São Paulo 1886-1936). In: SOUZA, M. A. A. et al. (ed.). Metrópole e globalização: conhecendo a cidade de São Paulo. São Paulo, SP: Editora Cedesp, 1999.

UN-HABITAT. Guía para el monitoreo de la Meta 11. Programa de las Naciones Unidas para los Asentamientos Humanos. Nairobi, 2003a. 
UN-HABITAT. The challenge of slums: global report on human settlements 2003. Earthscan, London, 2003b.

UNITED NATIONS. Principles and recommendations for population and housing censuses. Revision 2. Series M, n. 67/Rev.2. New York, NY: UN, 2008.

VAINER, C. et al. O plano popular da vila autódromo, uma experiência de planejamento conflitual. In: ENCONTRO NACIONAL DA ANPUR, 15., 2013, Recife, PE. Anais [...]. São Paulo, SP: Anpur, 2013.

VILLAÇA, F. Espaço intra urbano no Brasil. São Paulo, SP: Studio Nobel, 2001.

\title{
Sobre os autores
}

Larissa Souza Catalá é mestre em Demografia pela Universidade Estadual de Campinas (Unicamp), especialista em Pesquisa de Mercado Aplicada em Comunicações pela Universidade de São Paulo (USP) e graduada em Estatística pela Unicamp. É tecnologista em informações geográficas e estatísticas no Centro de Entrevistas Telefônicas Assistidas por Computador do IBGE (Cetac).

Roberto Luiz do Carmo é doutor em Demografia, mestre em Sociologia e sociólogo pela Universidade Estadual de Campinas (Unicamp). Professor livre docente do Departamento de Demografia, Instituto de Filosofia e Ciências Humanas da Unicamp e pesquisador do Núcleo de Estudos de População "Elza Berquó" (Nepo/Unicamp).

\section{Endereço para correspondência}

\author{
Larissa Souza Catalá \\ Instituto Brasileiro de Geografia e Estatística (IBGE) \\ Rua Equador, 558, 4ㅇadar, Santo Cristo \\ 20220-410 - Rio de Janeiro-RJ, Brasil \\ Roberto Luiz do Carmo \\ Universidade Estadual de Campinas (Unicamp), Instituto de Filosofia e Ciências Humanas \\ (IFCH) \\ Rua Cora Coralina, 100, Cidade Universitária Zeferino Vaz, Barão Geraldo \\ 13083-896 - Campinas-SP, Brasil
}

\section{Abstract}

The IBGE's concept of subnormal agglomerate and the precariousness of Brazilian urban infrastructure

This article addresses the limitations of the IBGE's subnormal agglomerate category to analyze socioeconomic, housing, and demographic inequalities and, specially, inequalities in access to basic urban infrastructure services in Brazilian cities. The text also considers the potential impact that the changes foreseen for the next Demographic Census will have on the analyses and public policies for improving urban living conditions. As a methodology, Discriminant Analysis was used to identify census sectors classified as common by IBGE, which had characteristics similar to those of subnormal sectors, in 2010, in selected Metropolitan Regions. Then, the types of sectors were related to the inadequacy of basic urban infrastructure services and the questions to be removed 
from the next Census were analyzed, in the light of the variables that discriminated most between subnormal and common sectors, according to the analyses carried out. The results showed that the subnormal and similar sectors identified were not enough to represent the urban areas with the greatest demand for adequate essential public services in 2010. The location of the sectors reflects much more about the precariousness of services than their condition of "subnormality". The relevance of electricity supply information and also of occupancy condition of households for the analysis about housing and urban infrastructure inequalities are highlighted. These variables are indicated to be removed from the universe questionnaire in the next census. Finally, the continuous valuation of property in the IBGE's concept of "subnormality" over the availability of adequate essential public services in urban areas is emphasized.

Keywords: IBGE. Subnormal agglomerate. Discriminant analysis. Metropolitan regions. Brazil.

\section{Resumen}

El concepto de aglomerado subnormal del IBGE y la precariedad de la infraestructura urbana brasileña

Este artículo aborda las limitaciones de la categoría aglomerado subnormal, del IBGE, para analizar las desigualdades socioeconómicas, habitacionales, demográficas y, sobre todo, de acceso a servicios básicos de infraestructura urbana en las ciudades brasileñas. El texto también considera los impactos potenciales que los cambios previstos para el próximo censo de población tendrán sobre los análisis y las políticas públicas para mejorar las condiciones de vida urbana. Como metodología, se utilizó el análisis discriminante para identificar los sectores censales clasificados como comunes por el IBGE que tenían características similares a las de los sectores subnormales, en 2010 en las regiones metropolitanas seleccionadas. Luego, se relacionaron los tipos de sectores con la inadecuación de los servicios básicos de infraestructura urbana y se analizaron las preguntas a ser eliminadas del próximo censo a la luz de las variables que más discriminaron entre sectores subnormales y comunes, según los análisis realizados. Los resultados muestran que los sectores subnormales y similares identificados no fueron suficientes para representar las áreas urbanas con mayor demanda de servicios públicos esenciales adecuados, en 2010. La ubicación de los sectores refleja mucho más la precariedad de los servicios que su condición de subnormalidad. Se destaca la relevancia de la información sobre el suministro de energía eléctrica y sobre la condición de ocupación de los hogares en el análisis de las desigualdades habitacionales y de infraestructura urbana, cuyas variables están indicadas para ser eliminadas del cuestionario del universo en el próximo censo. Por último, cabe destacar la valoración continua de la propiedad en el concepto de "subnormalidad" del IBGE en detrimento de la disponibilidad de servicios públicos esenciales adecuados en las zonas urbanas.

Palabras clave: IBGE. Aglomerado subnormal. Análisis discriminante. Regiones metropolitanas. Brasil.

Recebido para publicação em 02/10/2020 Aceito para publicação em 28/05/2021 